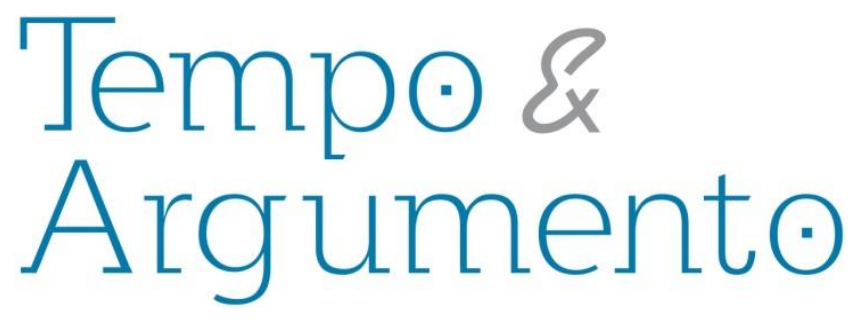

\title{
O tempo que alcancei. Narrativas sobre o passado na comunidade Cafundá Astrogilda do Quilombo de Vargem Grande (RJ) ${ }^{1}$
}

\begin{abstract}
Resumo
Ao refletirem sobre o seu passado, as famílias que organizaram o Quilombo de Vargem Grande, no Rio de Janeiro, narram os acontecimentos com significado que tem marcado a história do grupo, estabelecendo uma temporalização que versa sobre os fatos considerados socialmente relevantes e estabelecendo marcos da memória coletiva que respondem aos interesses e preocupações dos atuais grupos familiares que moram no maciço da Pedra Branca. Nesta reflexão, o tempo apresenta sua natureza social, a partir da constatação de que o ritmo da vida coletiva informa as temporalidades que operam na sociedade. No caso apresentado, as mudanças não são marcadas por datas, mas por "tempos" que ao serem designados articulam espaços e modos de habitar, dentre outros elementos. Esse modo de refletir sobre os tempos que marcam sua história parte de situações concretamente vividas pelos moradores e seus ancestrais da área de estudo, mas também responde às condições sociais de produção das memórias.
\end{abstract}

\author{
Luz Stella Rodríguez Cáceres \\ Doutora em Geografia pela Universidade \\ Federal do Rio de Janeiro (UFRJ). \\ Pesquisadora do Laboratório de Antropologia \\ da Arquitetura e o Espaço LAARES/IFCS/UFRJ \\ Estágio Pós-Doutoral no PPCIS/UERJ. \\ Rio de Janeiro - BRASIL \\ lunsella@gmail.com
}

Palavras-chave: Tempo. Temporalidade. Memória.

Quilombos - Rio de Janeiro.

\section{Para citar este artigo:}

RODRíGUEZ, Luz Stella. O tempo que alcancei. Narrativas sobre o passado na comunidade Cafundá Astrogilda do Quilombo de Vargem Grande (RJ). Tempo e Argumento, Florianópolis, v. 9, n. 22, p. 259 - 287, set./dez. 2017.

\section{DOI: $10.5965 / 2175180309222017259$}

http://dx.doi.org/10.5965/2175180309222017259

\footnotetext{
${ }^{1}$ Este trabalho contou com o apoio da_Fundação Carlos Chagas Filho de Amparo à Pesquisa do Estado do Rio de Janeiro (FAPERJ). Sou grata à acolhida que os membros da família Santos Mesquita me brindaram durante os meses de trabalho de campo; sua receptividade à minha companhia e às perguntas foram fundamentais para a escrita desta reflexão.
} 


\title{
The time I lived. Narratives about the past in the community Cafundá Astrogilda of Quilombo de Vargem Grande (RJ)
}

\begin{abstract}
Reflecting on their past, the families which have organised the "Quilombo" in Vargem Grande Rio de Janeiro narrate the events which have immediate significance to them, establishing a temporality which talks about the facts which are considered socially relevant, creating frameworks of collective memory which respond to the interests and worries of the actual familial groups. In the reflective process, time presents its social nature, from the confirmation that the rhythm of collective life informs the temporalities which operate within society. In the case presented, changes are not marked by "dates" but rather by "times" which are designated by name, articulating spaces and ways of inhabiting, amongst other elements. This way of reflecting about times, marks their history and situations, concretely experienced by residents of the area and their ancestors.
\end{abstract}

Keywords: Time. Temporality. Memory. Quilombos - Rio de Janeiro.

\section{Introdução}

O objetivo desta reflexão é evidenciar os marcos de pensamento comuns para um grupo de famílias que iniciaram um processo de reconstrução sobre o passado no marco da luta pela regularização fundiária quilombola. Este texto se propõe a explorar as narrativas que contam acontecimentos do passado e que têm significado para uma parte dos moradores do maciço da Pedra Branca, no bairro Vargem Grande, da zona oeste da cidade do Rio de Janeiro. De origem camponesa, essas famílias afrodescendentes, na sua maioria, compartilham uma história comum cujas memórias permitem traçar uma periodização que entrecruza os tempos privados e geracionais das memórias familiares com o tempo público. Ditas narrativas reúnem antepassados escravizados, compras de 
terras ao Banco de Crédito Mobiliário e a resistência às ameaças de expropriação que os habitantes do maciço foram expostos por parte dos administradores do Parque Estadual da Pedra Branca (PEPB).

Esta análise é decorrente do trabalho de campo que iniciei em Vargem Grande após o reconhecimento da comunidade quilombola realizado em setembro de 2014 pelo Estado brasileiro, mediante o certificado entregue pela Fundação Cultural Palmares (FCP). Por dez meses, convivi com habitantes do maciço da Pedra Branca, sendo acolhida principalmente pela família Santos Mesquita, cujos membros impulsionaram o processo de certificação quilombola e foram meus informantes privilegiados, particularmente Pingo e seus filhos, Sandro e Alexandre, e também Pedro, seu sobrinho. O trabalho de campo foi realizado antes de qualquer perícia antropológica dentro do marco legal e estava direcionado, inicialmente, à compreensão da percepção nativa da paisagem.

A etnografia me permitiu abordar um conjunto de fatos cotidianos ligados às memórias familiares, epistemologias ambientais e redes de parentesco (Rodríguez, 2016, 2017, 2017b). Porém, minha permanência em campo me aproximou também do repertório do processo organizativo local em torno da nascente questão quilombola, permitindo conhecer o cunho das suas demandas de reconhecimento étnico e territorial dentro de uma área de preservação ambiental.

\section{Antecedentes à organização quilombola. O tempo do parque}

Para compreender as condições sociais da produção das temporalidades ou classificações do tempo pelos moradores do quilombo de Vargem Grande, vale a pena destacar que a transformação de 12.500 hectares do maciço da Pedra Branca em parque estadual, em 1974, sob o governo estadual de Chagas Freitas, influenciou as atuais condições sociais dos moradores, camponeses na sua maioria. O momento de sua inauguração é referido localmente como o tempo do parque ${ }^{2}$ e impactou de forma significativa as formas de vida, configurando-se em um dos marcos da memória na forma que o passado é interpretado.

\footnotetext{
${ }^{2}$ Neste texto aparecem em itálico expressões e categorias nativas.
} 
A criação do PEPB teve uma influência significativa na redução da agricultura e acarretou mudanças nos estilos de vida locais. Em nome das políticas de conservação ambiental, as práticas de subsistência camponesa foram perseguidas. À época da fundação dessa unidade de conservação ambiental, se estimava a existência de 180 famílias que viviam da lavoura produzindo 300 mil cachos de banana e 20 mil caixas de laranja por mês. A faixa de cultivo abrangia quase a totalidade da área reservada hoje para o parque; banana, caqui e laranja foram os principais produtos da área e as duas primeiras lavouras continuam sendo de importância produtiva para as famílias agricultoras que ainda persistem.

O PEPB, administrado na atualidade pelo Instituto Estadual do Ambiente (INEA), nunca teve uma política fundiária, causando uma condição de incerteza jurídica nos moradores tradicionais e criando sérios conflitos. A despeito de não serem removidos, os moradores tiveram negadas as suas formas de territorialidade e passaram a sofrer impedimentos crescentes para a realização de determinadas atividades e usos do espaço sem nunca acontecer nenhuma indenização (SOARES, 1981).

Vale a pena aqui lembrar que as primeiras medidas institucionais realmente significativas para a implantação do PEPB datam de 1991, quando Darcy Ribeiro coordenou o Projeto Floresta da Pedra Branca em conjunto com a equipe do então Instituto Estadual Florestal (IEF). O marco da política naquela época eram os preparativos para a realização da Conferência das Nações Unidas para o Meio Ambiente e o Desenvolvimento (ECO 92). Sob o conjunto de diretrizes do Sistema Nacional de Unidades de Conservação (SNUC) nos anos 2000, o PEPB ganhou nova face institucional. O traço mais visível desta orientação foi a demarcação do espaço e a explicitação da existência do Parque através de placas normativas, de portais de entrada e a construção de um centro de visitação no local chamado Pau da Fome (CCPEPB, 2012). Em agosto de 2001, uma iniciativa conjunta do IEF, da Fundação Roberto Marinho e do World Wild Found (WWF) teve como objetivo revitalizar o PEPB mediante ações de demarcação de controle institucional sob o território do Parque e a construção e reforma de instalações para o fomento da visitação, seguindo até então os lineamentos de um ambientalismo conservador. 
Com a redemocratização do Brasil, as perspectivas que exigiam a participação cidadã em várias esferas foram se modelando, ainda que timidamente, possibilidades de intervenção de setores populares em esferas de decisão, permitindo a construção de espaços de negociação com o Estado (FONSECA, 1996). Em relação às políticas de meio ambiente, tornou-se exigência legal do SNUC, em 2006, o processo de formação dos conselhos consultivos nas unidades de conservação ambiental (CCPEPB, 2012).

No caso do PEPB, a participação local deu seus primeiros passos em 2009, quando um conselho consultivo veio a se constituir com o intuito de permitir que grupos organizados de moradores, agricultores e instituições ocupassem um espaço de participação. O objetivo do conselho era garantir acesso à informação a todos os setores sobre temas de interesse. A articulação do conselho teve seu primeiro grande impacto após a elaboração do plano de manejo de 2012 e a tentativa de pô-lo em marcha. A proposta de fundo desse plano era um projeto de regularização fundiária que colocava em risco a permanência dos moradores na área do parque (CCPEPB, 2012).

Após a publicação do plano de manejo em Diário Oficial, o conselho consultivo teve um papel na divulgação do plano entre os moradores, o qual teve como desdobramento uma mobilização social. Segundo Annelise Fernandez (2016), em diversas localidades do maciço foram realizadas reuniões para informar moradores não organizados sobre seus direitos territoriais e os riscos da política de regularização fundiária. O plano elaborado pelo INEA propunha a regulamentação da utilização do solo ratificando a proibição de qualquer agricultura no local. $O$ mesmo documento recomendava como próximo passo do instituto, um cadastro de todas as ocupações na área objeto de proteção ambiental.

À época, Eduardo Lardosa, chefe do Serviço de Planejamento e Pesquisa Científica do INEA enfatizava, em depoimento à Revista Piauí, que em prol da proteção do meio ambiente se desconheciam os direitos das populações que ancestralmente habitavam o parque:

O parque foi criado para garantir a floresta, a biodiversidade, o patrimônio geológico, e isso, obviamente, em algum momento conflita com a existência das atividades agrícolas, quando você cria uma unidade de conservação, principalmente de proteção integral, o interesse da 
sociedade prevalece sobre interesses particulares, de uma ou outra pessoa ou de pequenos grupos. Vamos estudar caso a caso, estamos cientes de que há pessoas que tiram de lá sua sobrevivência e que estão historicamente ligadas ao local, mas o que acontecerá com os ocupantes só será definido no fim do cadastramento. (VIEGAS, 2013, p 5)

Em março de 2013 aconteceu no Alto Mucuíba, em Vargem Grande, uma reunião dos moradores da área do parque que viria a ser decisiva. Nela, afloraram as falas dos moradores mais antigos, invocando seus vínculos de pertencimento com o lugar, suas relações de parentesco e vizinhança e sua descendência de africanos escravizados. Uma mobilização em torno da "tradicionalidade" surgia então nesse momento (FERNANDEZ, 2016, p. 139).

Para os atuais líderes do movimento quilombola, o combustível para sua mobilização foi a perseguição empreendida por parte dos administradores do parque, que foi se tornando insustentável. Multas por acréscimos e reformas de suas casas, restrições às roçadas e plantações tornaram-se situações cotidianas para os moradores, que se sentiam acuados e constantemente vigiados. Assim, o extremo desrespeito conformou uma gramática moral (HONNETH, 2003) na luta pelo reconhecimento como grupo.

Até hoje, muitos moradores acreditam que são fotografados e monitorados desde o ar. Segundo um dos meus informantes, o limite da paciência foi marcado pelos momentos em que a polícia ambiental entrou armada ao longo do ano de 2012 em alguns domicílios sem nenhum aviso ou ordem e em franca atitude amedrontadora, com o objetivo de liberar aves canoras. Para os moradores do maciço, esses eventos aceleraram a organização, levando os moradores a procurarem a academia e Organizações não governamentais (ONGs). Essa aproximação desdobrou-se numa trama de relações e alianças que foram se modificando e alargando os horizontes de atuação de cada um dos atores envolvidos. Apesar das tensões internas e dos muitos não consensos, as pessoas se uniram nos questionamentos às ações dos órgãos ambientais que fiscalizavam o uso do seu território. Essa cumplicidade e união entre os moradores do maciço formalizaram um contexto de luta e resistência diante das leis ambientais estaduais consideradas arbitrárias por eles. 


\section{As condições do surgimento do passado como ferramenta de luta}

A questão da tradicionalidade veio tomar uma forma mais precisa a partir da intervenção de “Panela de Barro. Instituto étnico, ambiental e cultural”, liderado por Mário Rosa, experimentado militante negro dedicado à defesa da diversidade religiosa e ligado ao Conselho Municipal de Defesa dos Direitos do Negro (COMDEDINE)³. Numa primeira reunião convocada pela cooperativa de agricultores Agro-Vargem, os membros de Panela de Barro se colocaram à disposição da comunidade e apresentaram aos assistentes a legislação brasileira para comunidades tradicionais em áreas de proteção ambiental e para comunidades quilombolas.

O artigo 68 das Disposições Transitórias da Constituição Federal ${ }^{4}$, que garante a posse das terras remanescentes de quilombo em caráter coletivo e inalienável, e o Decreto $4887 / 2003^{5}$ foram apresentados para a comunidade como ferramentas para a reivindicação de direitos territoriais, indicando um novo cenário de lutas e disputas concretas e simbólicas em torno da noção da identidade e do território ocupado ou percebido enquanto legítimo. Como tem sido refletido por Mattos (2005) para outros contextos, o surgimento dos marcos legais sobre os direitos territoriais das comunidades dos quilombos promoveu um processo de revisão histórica e de consequente mobilização política, que conjugava a afirmação de uma identidade negra no Brasil à difusão de uma memória da luta dos escravos contra a escravidão e cujos efeitos ainda se vertem. Para Andreas Huyssen, quando a conjuntura muda, os problemas são recolocados de forma diferente, lembranças que foram contidas ressurgem, principalmente como "resultado de um novo amálgama entre a lembrança do passado e um presente político" (HUYSSEN, 2004, p. 16).

Esse contexto promoveu o surgimento de novas condições sociais no processo de produção do passado, complementando as existentes representações coletivas do tempo. O quadro inicial de persecução por parte dos administradores do PEPB, acionado

\footnotetext{
3 Organização de consulta e interação da comunidade com o governo da cidade do Rio de Janeiro.

${ }^{4}$ Aos remanescentes das comunidades de quilombos que estejam ocupando suas terras é reconhecida a propriedade definitiva, devendo o Estado Ihes emitir os títulos respectivos.

${ }^{5}$ Decreto que regulamenta o procedimento para identificação, reconhecimento, delimitação, demarcação e titulação das terras ocupadas por remanescentes das comunidades de quilombos.
} 
inicialmente para sustentar o reconhecimento dos direitos da comunidade sobre o território do maciço foi cedendo lugar para uma reflexão sobre memória e passado. Itens que têm servido desde a década de 1980, nos mais variados contextos, como instrumentos para estruturar ações de construção identitária em contextos de lutas que passam pela definição de uma versão compartilhada do passado de um dado grupo social. Isso não significa que as buscas pelo passado e as genealogias que os atuais quilombolas levantam hoje, se fundamentem apenas na pretensão de serem incluídas para fazer jus à proteção e amparo dos seus direitos; essas procuras também manifestam a relação que se tece com a ordem do tempo dominante.

A ONG Panela de Barro teve um papel importante na obtenção da certidão de comunidade remanescente de quilombo junto à Fundação Cultural Palmares. Para construir a solicitação do reconhecimento, a ONG elaborou um relato sintético da trajetória do grupo junto à comunidade. Para tal, membros da ONG indagaram sobre o passado da comunidade, reuniram-se com membros da família Santos Mesquita e especialmente com Jorge, mais conhecido como Pingo, tido como especialista no passado e conhecedor de causos e relatos do passado da serra de Vargem Grande. Histórias sobre as pessoas do tempo de antigamente foram resgatadas, partidas de nascimento, casamentos e óbitos e escrituras de propriedade dos lotes foram revisadas e enxergadas como provas da presença histórica das famílias no maciço ${ }^{6}$.

A existência de um antigo terreiro de umbanda desativado em 1962, data em que morreu Celso dos Santos Mesquita, um dos fundadores da casa, se tornou um ponto de

\footnotetext{
${ }^{6}$ De acordo com a Instrução Normativa $n^{\circ} 49$, de 29 de setembro de 2008 , o início do procedimento de titulação passa a estar condicionado à apresentação de certidão emitida pela $\mathrm{FCP}$, de Registro no Cadastro Geral de Remanescentes de Comunidades de Quilombos (artigo 7, parágrafo 3). A emissão da "certidão de autodefinição como remanescentes dos quilombos" (necessária para fins de inscrição da comunidade no Cadastro Geral de Remanescentes das Comunidades dos Quilombos) está condicionada a determinados "procedimentos", entre os quais, a apresentação "de relato sintético da trajetória comum do grupo (história da comunidade)" e a remessa, "caso a comunidade os possua, de dados, documentos ou informações, tais como fotos, reportagens, estudos realizados, entre outros, que atestem a história comum do grupo ou suas manifestações culturais" (artigo 3, III e IV). Tal regulamentação, ao contrário do que previa a Portaria anterior (Portaria $n^{\circ} 6$, de 2004), impõe que a comunidade justifique (ou até mesmo prove) sua ascendência quilombola, sendo que a declaração, em si, passa a não ser mais suficiente. Pela regra anterior, o Instituto Nacional de Colonização e Reforma Agrária (INCRA) poderia iniciar o processo de titulação com a apresentação, pela comunidade, de uma "simples declaração" de autodefinição como remanescente de quilombos.
} 
partida para as primeiras indagações. Iniciado em 1934, o terreiro foi conduzido por Astrogilda e Celso, pais de Pingo. As memórias das práticas religiosas no terreiro se somavam à história do guia espiritual da casa, Pai Tertuliano, entidade que segundo as versões nativas tinha sido escravizada em algum lugar de África e tinha sido cultuada pelos escravizados das fazendas de Vargem Grande. Esses elementos chamaram a atenção dos membros da ONG porque as memórias familiares dessa religiosidade popular estabeleciam um vínculo com a escravidão de africanos e por tal viraram o sustento principal do pedido da certificação quilombola. O tempo dos escravos foi se tornando mais presente e Pai Tertuliano se tornou, então, um importante elo simbólico entre o passado e as demandas políticas do presente (Rodríguez, 2017). Panela de Barro também foi importante na denominação da comunidade quilombola ao sugerir que o nome registrado fosse uma homenagem às mulheres e a mais indicada seria a matriarca Astrogilda, incluindo no título da comunidade a localização do terreiro espírita, no caminho de Cafundá.

A partir desse momento, uma pedagogia sobre identidade e direitos étnicoterritoriais foi posta em marcha. As categorias de quilombolas e remanescentes de quilombo começaram a ser acionadas, especialmente para fora da comunidade nos distintos processos de negociação com o Estado e demais instituições. Internamente, os habitantes do maciço vestiram com dificuldade a categoria, preferindo ainda serem chamados como agricultores ou lavradores, aqueles que estão ligados com essa atividade. Indiscutivelmente a emergência de novos sujeitos políticos impõe, entre outras coisas, uma discussão crítica sobre as condições sociais de produção do passado e as formas como as memórias começam a serem constituídas sob enquadramentos políticos (POLLAK, 1989). Como argumenta José Maurício Arruti, quilombo é uma categoria analítica em construção e em disputa. Nem tanto “em função de seu caráter polissêmico, aberto, com grandes variações empíricas de ocorrência no tempo e no espaço. Mas uma disputa em torno de como o plano analítico se conecta com os planos político e normativo" (ARRUTI, 2008, p. 315-316).

Em outro sentido, Flávio Gomes e Petrônio Domingues (2013) indicaram que o momento político das comunidades remanescentes de quilombo tem dado visibilidade a 
um campesinato negro, formado no processo de desagregação da escravidão no Brasil. Esse desvendamento coloca em evidência, principalmente, formas singulares de controle do acesso à terra, historizadas oralmente mediante a categoria "tempo". No caso de Vargem Grande cada "tempo" coloca em evidência as relações sociais que contrastam de forma significativa com o que existia no período anterior e que ganham inteligibilidade na medida em que se referem a estruturas de periodização efetivamente generalizadas e referenciadas à vivência familiar dos narradores.

O caso em questão também é pertinente para ilustrar as experiências da pósemancipação, pois a experiência dos remanescentes de quilombos no Brasil não se esgota num dado passado da escravidão (GOMES; DOMINGUES, 2013). Por tal motivo, Flávio Gomes vem insistindo que para entender as formações desse campesinato negro sejam consideradas as diversas experiências de ocupação de terra nas últimas décadas do século XIX e início do XX, dentre as quais se destacam terras herdadas de quilombolas/escravos fugidos e seus descendentes da escravidão; doações de senhores ou ordens religiosas a ex-escravizados; terras compradas por libertos e herdadas pelos seus descendentes e terras conseguidas do Estado em troca de participação em guerras, etc. Seguindo essa hipótese, vejam a continuação de como as formas de ocupação da terra foram narradas por alguns dos moradores de Vargem Grande que entrevistei durante o período de trabalho de campo.

\section{Três marcos da memória em Vargem Grande}

As formas como os membros da família Santos Mesquita interpretam o passado estabelecem conexões com a história do bairro de Vargem Grande mediante a periodização de lembranças que se constituem em marcos de pensamento comuns que apontam para a distinção de três momentos que têm mais de uma maneira de serem denominados, mas que grosso modo se dividem em tempo do Banco de Crédito Imóvel, tempo do Parque e tempo dos escravos. Com essas categorias, a experiência social do tempo é ordenada, outorgando a este um sentido. Destaca-se, nesse caso, a relevância nas memórias familiares do impacto das diversas medidas legais de profundo alcance na 
redefinição das relações cotidianas entre as pessoas e a terra e o grupo social e o Estado. Essa maneira episódica de conceber as camadas do tempo tem sido identificada em outros contextos etnográficos (PIETRAFESA DE GODOI, 1999; GOW, 1991; SOARES, 1981), informando a maneira como as temporalidades são instauradas socialmente.

Nessa temporalização, as mudanças não são marcadas por datas, mas por “tempos” que são designados por nomes, articulando espaços e modos de habitar, dentre outros elementos. O modo de refletir as mudanças que marcam a história parte de situações concretamente vividas pelos moradores e seus ancestrais. Daí que nas conversas com os habitantes sobre o passado, as expressões isso eu alcancei, isso eu não alcancei, me contaram ou assim ouvi dizer sejam usuais para denotar aquilo que faz parte da experiência vivida e aquilo sobre o que se tem notícias, mas não a certeza por não ter participado (GOW, 2001; PIETRAFESA DE GODOI, 1999).

Acatando que só é temporalizado aquilo que é considerado socialmente relevante, entende-se que esses marcos da memória coletiva respondam aos interesses e preocupações das famílias Santos Mesquita, Lacerda Drumond, Pereira, Alves de Andrade e Rodrigues, entre outros núcleos que atualmente moram dentro da área do Parque Estadual da Pedra Branca. Ditos marcos enfatizam as pegadas que aqueles períodos deixaram na memória social. Dá-se importância aqui aos fatos com significado coletivo definidos desde o contexto presente (HALBWACHS, 1989), pois o passado, sabe-se, não é estático, e muda quando reexaminado e escrutado nas suas ressonâncias mais profundas.

A exploração dessas temporalidades é feita desde o presente etnográfico, seguindo as reconstruções e perguntas atuais das famílias habitantes do maciço sem seguir a ordem cronológica linear de um tempo irreversível da ciência histórica, e que por vezes resistem aos trabalhos de enquadramento das memórias. O que mais interessa aqui é ressaltar a superposição de tempos que a narrativa oral insinua, aglutina numa simultaneidade de diferentes etapas temporais, desafiando o tempo oficial marcado pelos eventos fundadores. Além do limite propriamente dito das narrativas contadas, essa sincronia e aparente sobreposição resulta perturbadora para uma distinção histórica lineal (HARTOG, 2013), já que na narrativa oral, passado e presente se fundem, moldam-se um ao outro, de um modo que permite que as memórias conformem um prisma através 
A perspectiva a partir da qual se olha o passado proporciona novas dimensões do mesmo (HALBWACHS, 1989) e certamente novas possibilidades para explorá-lo. A reconstrução do passado a partir dos depoimentos dos entrevistados reúne elementos que desafiam a separação ontológica entre a memória transmitida oralmente e a história. Em consequência, esse passado é uma mistura de olhares que tem por base a tradição oral, as formas de acesso à terra e as marcas do passado na paisagem, abarcando também objetos antigos, vestígios e ruínas, documentos bancários, registros de cartório e a narrativa contida em "O sertão Carioca”, de Armando Magalhães Corrêa, livro cuja circulação entre vários moradores colabora para compor suas memórias.

Ao longo desta reflexão se perceberá que os tempos socialmente definidos remetem a regimes de propriedade da terra, produção e sociabilidades. Assim, o tempo do banco é a forma como os mais antigos de Vargem Grande designam o período da racionalidade imobiliária em que o Banco de Crédito Imóvel $(\mathrm{BCl})$ se tornou o maior dono das terras que outrora pertenceram ao Mosteiro de São Bento. Pertencentes aos monges, as antigas fazendas de Vargem Grande, Camorim e Vargem Pequena foram vendidas para a Companhia de Engenho Central e, no ano seguinte, passaram para as mãos do Banco de Crédito Móvel no final de século XIX. Ante à incapacidade de pagamento por parte da companhia, o $\mathrm{BCl}$ embargou as terras e começou a administrar seguindo o modelo do Mosteiro, na base de arrendamentos anuais, ao mesmo tempo em que procurava sua venda aos antigos posseiros. Os aluguéis eram arrecadados por pessoas que moravam na localidade, verdadeiros administradores que chegavam a exercer o papel de capangas (CORRÊA, 1936). O domínio do $\mathrm{BCl}$ na zona oeste se deu sobre o desconhecimento dos aforamentos ou livres concessões que os monges proprietários tinham feito aos seus escravos ou ex-escravizados. Fridman (1999) destaca que os escravos dos beneditinos possuíam pequenas roças para seu sustento e nessas terras devem ter permanecido quando alforriados, em 1871. Calcula-se que, para o momento da transação de terras, o maciço estivesse habitado por cerca de seiscentas famílias (GAZETA DA TARDE, 1891 apud DORIA, 2017). 
A partir da década de 1920, os aluguéis sofreram incrementos exagerados que duplicaram e triplicaram o valor inicial, sendo o despejo a medida tomada pelo $\mathrm{BCl}$ pelo não pagamento das prestações. A era das remoções levadas a cabo pelo $\mathrm{BCl}$ contra os inadimplentes é um dos capítulos mais marcantes da memória local, dada a violência dos despejos, que tinham como prática a destruição das vivendas, quando não a queima dos poucos bens que as pessoas tinham. Isso viveu meu pai, ele que alcançou e nos contava, explica Pedro para relatar as cenas de pessoas na beira dos caminhos sentadas sobre seus pertences e planejando o que fazer; imagens recorrentes transmitidas oralmente entre as gerações posteriores.

As ruínas de casas destruídas pelo extinto banco permanecem como marcas na paisagem e são assinaladas pelos atuais moradores como testemunhas dessa época para aqueles que não a vivenciaram. Desta forma, muitas casas do tempo do banco permanecem "visíveis" e "tangíveis". Mencionadas de forma constante, existem no espaço da memória, fala-se delas como se ainda estivessem diante dos olhos do narrador que lembra formas desfeitas e deste modo afirma direitos, relações, pessoas e eventos, criando sobre a terra uma grande meditação sobre os despojos.

O despejo foi então um mecanismo efetivo para disciplinar o pagamento em dia ao banco, o qual permaneceu até meados dos anos 60. Muitos dos atuais moradores guardam com zelo os carnês das prestações mensais com os quais seus pais efetuaram os pagamentos das suas terras. Ditos documentos se constituem tanto em suportes das suas memórias, como na garantia de ter pagado pela terra onde moram e de estarem ali muitos anos antes do tempo do parque. No tempo do banco muitos lavradores conseguiram pagar suas dívidas e tornaram-se proprietários, mas outros tantos continuaram como arrendatários.

O mesmo papel de demonstrar a presença e arraigo das famílias à terra pode cumprir, em princípio, as pequenas coleções pessoais de objetos antigos que vários moradores possuem e fazem questão de exibir: ferramentas, fotografias, armas de caça, gaiolas, estilingues, vitrolas, banheiras de madeira, panelas de cobre, esculturas de madeira, relógios cuco, selas, estribos e armaduras para montar cavalos e bercinhos e roupas de bebê, todas herdadas dos parentes do tempo de antigamente. 
A formação dessas coleções não é apenas uma estratégia política que faz uso da historicidade contida nos objetos. Dita prática não pode ser vista de forma unidirecional, a partir de uma abordagem "presentista" (HARTOG, 2013) na qual se supõe que um presente soberano continuamente imprime sua marca em um passado infinitamente maleável, nem como uma tentativa de instrumentalizar as lembranças do passado através das coisas e heranças familiares. Uma melhor compreensão das relações que as pessoas estabelecem com esses artefatos vem nos falar tanto da permanência da aura das coisas (BENJAMIN, 1989), como de uma forma afetiva de se relacionar com o passado e manter vivas as relações com os parentes mortos, um modo que os habitantes narram a si mesmos através de objetos antigos.

É no tempo de antes que é situado Manuel Sérgio dos Santos Mesquita, que viveu nas terras que estavam localizadas à margem esquerda do Rio Paineiras, rio que já foi o limite entre os antigos distritos de Guaratiba e Jacarepaguá. Sobre ele se conta que foi maçom, e a relevância desse dado vem da contribuição da maçonaria para a abolição da escravidão. A aura que envolvia as sociedades secretas era, não raramente, associada à bruxaria, quando não a assuntos do demônio. Corria a lenda então que, por ser maçom, Manuel Sérgio tinha também certos poderes mágicos e proteções reforçadas vindas das suas misteriosas alianças.

Manuel Sérgio, assim como muitos posseiros da época, obtinha seu sustento da produção de carvão vegetal e da lavoura de subsistência; a banana era, como hoje, uma das principais culturas. Tinha uma tropa de doze burros, e deles se servia para escoar sua produção para Rio da Prata, Taquara e Curicica. Casou-se com sua prima Bernardina dos Santos Mesquita, dando origem a um dos mais densos núcleos de parentesco na vertente de Vargem Grande do maciço de Pedra Branca.

Celso, Nilo, João, Alzira e Veiga foram os cinco filhos da união mais antiga que os atuais descendentes têm memória. Celso casou-se com Astrogilda, Nilo com tia Mocinha Mesquita, João com tia Coleta Mesquita, Alzira, mais conhecida como tia Xoxó, casou-se com João Novaes e Veiga com tia Senhora Mesquita. Era raro se casar com alguém de fora, Tia Xoxó foi a única que escolheu para marido um nordestino que teria estado a serviço do bando de Lampião. A preferência pelas alianças entre primos era uma 
estratégia para preservar a terra dentro do patrimônio familiar. Esse costume estabeleceu as bases para uma autêntica sociedade de primos, como alguns dos locais costumam denominar de forma jocosa.

Das cinco uniões relatadas acima resultou uma linhagem de parentes cujos laços de sangue deixaram sua clara inscrição na paisagem do maciço da Pedra Branca. A terra de Manuel Sérgio foi pouca para todos os seus filhos e alguns deles também se endividaram com o $\mathrm{BCl}$ para comprar suas terras. É o caso de Nilo de Santos Mesquita, que chegou a pagar pelo seu sítio, denominado Cafundá Vargem Grande de Guaratiba, 97 parcelas de "cinquenta e sete mil trezentos e doze réis [sic]". Como ele, muitos moradores guardam os carnês de pagamento para demonstrar que a dívida com o $\mathrm{BCl}$ foi saldada.

De modo geral, as terras do maciço da Pedra Branca não são apenas uma paisagem ecológica contínua tal como o estabelecimento do parque pretendeu fundar. No exemplo anterior, essas terras estão definidas e classificadas por uma série de direitos de propriedade, contratos de venda, hipotecas e contratos de arrendamento que superpostos marcam o espaço e configuram a memória jurídica do grupo (HALBWACHS, 1989). Ditos mecanismos de acesso à terra não desapareceram com a posterior fundação do parque, ainda permanecem de forma ativa entre os atuais moradores.

Os relatos registrados durante o meu trabalho de campo deixam vislumbrar todo um modo de vida ordenado segundo determinados valores. A noção de família e parentesco, base da sua construção interna, ocupa o primeiro lugar, e a propriedade das terras aparece também de forma destacada, onde a agricultura combinada com a extração do carvão são colocadas como parte da memória e da identidade originária do grupo. A partir dessa perspectiva, temos dois elementos constantes que vêm a guiar as indagações sobre o passado do atual movimento quilombola: a família e a terra que, interdependentes, tecem a memória e o espaço. A memória se espacializa na paisagem, pois ela própria é uma narrativa de espaço e por meio dela se constrói a história fundiária da área e a genealogia das atuais famílias. 
As terras da família Santos Mesquita estavam do lado esquerdo do Rio Paineiras e por esse limite se distinguiam das terras da família Vieira, localizadas ao lado direito do mesmo rio. Ainda que nenhum dos descendentes atuais da família Vieira se dedique à produção agrícola, as suas terras são identificadas e localizadas espacialmente pelos atuais moradores que relatam os contratos de arrendamento que os Vieira faziam a lavradores sem-terra e que ainda subsistem.

O tempo do banco corresponde à época do auge da família Vieira, uma das mais acaudaladas da região. Suas origens se remontam ao português Elisiario Ferreira Vieira, pai de Pedro, Nico João, Elísia e Ruth. Nico e João foram os irmãos que mais acumularam terras em Vargem Grande; já Pedro, além dos terrenos nessa localidade, adquiriu vários imóveis na região da Praça Seca.

A família Vieira chegou a ser dona de boa parte de Vargem Grande e, conforme os interesses, compravam barato os terrenos e assim foram incrementando seu capital. A terra não era o único sustento do poder econômico dos Vieira, mas sim uma moeda de troca corriqueira. Quando membros de famílias pobres morriam, era comum que seus parentes procurassem empréstimos com os Vieira para pagar o enterro do defunto. A garantia do empréstimo era uma hipoteca sobre o lote que, frente à impossibilidade dessas famílias honrarem suas dívidas, terminava sendo adicionado ao patrimônio dos Vieira.

O patrimônio da família Vieira também se incrementou com o único moinho de fubá, do qual Nico era dono, usado por todos os produtores em troca de uma parte de sua produção. Por outro lado, João Vieira era proprietário de um armazém muito conhecido na região, apelidado localmente de Tira-Couro, devido aos preços abusivos das mercadorias. Os mais velhos gostam de descrevê-lo como um estabelecimento onde se podia encontrar toda sorte de mercadorias dos secos e molhados como açúcar, arroz, macarrão, carne seca, óleo aos tecidos e toda sorte de gêneros manufaturados.

As pessoas lembram que o Tira-Couro vendia muitos artigos importados, objetos de cutelaria, recipientes de cerâmica, ferragens, ferramentas, artigos têxteis; velas, lamparinas e lampiões, sal, fósforos, e assim por diante. Também compõem as memórias 
do armazém a oportunidade de beber e encontrar, fora do ambiente doméstico, parentes e vizinhos, o que tornava o local um cenário propício para brigas e confrontos. Assim, as trocas comerciais não eram a única dimensão social do armazém, ele também era um importante ponto de reunião, socialização e troca de notícias e informações. Por isso, também era o espaço onde as tensões entre famílias pobres e ricas e as fofocas ficavam permanentemente expostas.

O armazém não existe mais, mas o ponto onde estava situado ainda é reconhecido por esse nome. A memória social associa o tempo do banco com o tempo dos Vieira, que também é o tempo do Tira-Couro e que teve como papel central ser o ponto de conexão entre a serra e a cidade, o espaço de troca entre os produtos da roça e as mercadorias que vinham de fora. Da serra desciam os produtos a serem embarcados nos caminhões dos intermediários e do armazém. Os antigos lavradores subiam às suas casas as mercadorias que não produziam nas suas roças. Era nesse armazém onde os produtores de carvão, que era a população mais pobre, sem condição de ir aos grandes centros de comércio urbano, vendiam sua produção a preços baixos, ou a trocavam por mercadorias que sempre eram mais caras, se envolvendo em ciclos de endividamento sem fim.

O tempo do banco é o tempo de antes do parque, é o tempo da fartura e da fertilidade: dava-se de tudo e muito, explicam os atuais moradores, e comparado às restrições impostas pelo parque é ressaltada pelos agricultores a liberdade existente e o respeito ao uso do solo. Frente ao esvaziamento populacional que a fundação do parque propiciou, o tempo do banco é enxergado como um tempo em que abundavam vários núcleos familiares que espalhavam suas casas e culturas ao longo da serra. Olhando a macega e o mato fechado que terminou por encobrir os caminhos que eram avenidas de tanto trânsito que tinham; um dos meus interlocutores adverte: estava tudo trabalhado, $e$ hoje não fica nada. O tempo do parque é então o abandono massivo do trabalho agrícola e a vinculação dessas dos antigos lavradores a trabalhos urbanos. Foi o fim dos sujeitos puramente rurais que, justamente para poderem se manter, buscaram trabalhos assalariados no asfalto. 
Contudo, a diferenciação entre o tempo do banco e o tempo do parque não idealiza o primeiro que corresponde ao período da pós-abolição, também foi o tempo dos ciclos de dívidas creditícias, da vida dura na roça que como única forma de subsistência requeria do sacrifício para tirar a produção de carvão e banana a lombo de burro pelos caminhos íngremes do maciço. Essa experiência da dificuldade foi a base de uma adaptação criadora à realidade existente. Trata-se também de uma época marcada pelas tensões em torno da posse da terra, que como veremos ainda se reproduzem sob outro regime com a fundação do Parque Estadual da Pedra Branca (PEPB) em 1974.

O tempo do banco é também o tempo do sertão carioca ${ }^{7}$, nome da obra de Magalhães Corrêa que veio a constituir-se num marco da memória social, em cujas páginas muitos dos atuais moradores se reconhecem, estimando como muito acertada a representação que ali se propõe. Ao oferecer uma prova da presença dos lavradores desde antes do tempo do parque, a obra de 1936 se presentifica nos dias de hoje das formas mais variadas, se consagrando como um tempo de referência de caráter mítico, ao introduzir um princípio de ordem no universo e estruturar o pensamento humano (LEVIS-STRAUSS, 1989).

As dimensões míticas deste marco temporal são aprofundadas por mim em outro trabalho em andamento, mas cabe aqui resgatar que o livro "O sertão carioca" tornou-se um retrato do tempo de antes ou de antigamente ao encontrar eco nos atuais moradores, quando estes distinguem alguns dos parentes e vizinhos, já falecidos, e que no livro são referidos por nome, idade e ofício. Da mesma forma, sítios, caminhos e fazendas descritos pelo autor são localizados e identificados com exatidão no espaço e na memória pelos moradores. Por sua vez, a persistência na paisagem desses elementos, ora como sobrevivências, ora como ruínas, ora como lembranças vividas, faz com que as pessoas confiram ao livro uma aura de autenticidade, tornando-o um testemunho das mudanças e permanências sociais e materiais da área.

\footnotetext{
7 O Sertão Carioca foi um termo cunhado pelo naturalista Magalhães Corrêa, autor do livro que leva esse título, e o usa para denominar as terras que compreendiam as antigas freguesias rurais do Rio de Janeiro: Campo Grande, Guaratiba, Jacarepaguá, Irajá e Santa Cruz.
} 
Armando Magalhães Corrêa era um naturalista autodidata que exercia o cargo de conservador na seção de História Natural no Museu Nacional. Seus interesses conservacionistas em torno da natureza antecipavam a chegada do tempo do parque. Após ter caracterizado a especificidade "natural” do espaço em questão, propôs esforços no sentido de preservar e isolar o sertão carioca dos efeitos nefastos do contato dos sertanejos com o mundo urbano, ao tempo que defendia a necessidade de uma legislação imediata para proibir e punir a caça e o derrubamento das florestas. Magalhães previa, então, anos antes da criação do primeiro parque nacional brasileiro, a necessidade de haver áreas a serem submetidas a formas mais severas de proteção (ANDRADE; DRUMOND, 2005).

Desta forma, o atual PEPB terminou por consumar um dos sonhos de Magalhães Corrêa, ao se erguer como uma figura de reordenamento espacial em Vargem Grande. A implementação dos limites do parque a partir da cota de 100 metros além de um marcador físico na paisagem é um marco na memória dos moradores antigos e novos. $O$ PEPB não denota o início de uma idade completamente nova, pois ela propõe uma interpenetração dos tempos. As terras dos lavradores ficaram emolduradas dentro de uma área de preservação ambiental, mas sem jamais incorrer em indenizações por desapropriação, nem terminando as antigas relações de parceria, contratos de aluguel e atos de compra e venda, os quais continuaram a mediar o acesso à terra entre parentes e vizinhos à revelia da legislação ambiental.

O tempo do parque também é conhecido como o tempo do Ibama e o tempo do INEA. Sem se importar que a instituição encarregada e sua política tenham mudado, para os nativos a função punitiva do ambientalismo tem se mantido, sustentada na desvalorização e estigma que têm sido imputados à agricultura que, para os nativos, mais do que fonte de sustento é fonte identitária. A concepção estritamente técnica do meio ambiente que naqueles anos da ditadura guiou a criação do PEPB teve inegáveis impactos sobre o estilo de vida dos agricultores. Ao longo dos anos, uma série de proibições, nem sempre fixas, nem totalmente possíveis de supervisionar foram tomando forma para garantir a presença de uma unidade de conservação na metrópole carioca. 
Para atingir esse propósito, os responsáveis ambientais designados para zelar pela área passaram a regulamentar e inibir a ocupação do solo nas áreas do maciço. Para os agricultores em escala comercial de banana e caqui que ali haviam se estabelecido, permanecer na área significou a adaptação das suas atividades produtivas às restrições impostas pela administração do PEPB. Entre as medidas tomadas contam: a proibição de roçar os terrenos, de fazer queimada, de expandir as áreas cultivadas, de fazer melhoria nos caminhos construídos por eles mesmos, impedindo assim a utilização de meios de transporte mais modernos, motivo pelo qual o escoamento da produção continua sendo feita hoje, em boa medida, mediante burros que levam nos seus lombos jacás confeccionados artesanalmente.

Deste modo, com as regulamentações dos órgãos ambientais, foi penoso não só se dedicar às atividades agrícolas, como já exposto, mas evidentemente o próprio ato de habitar dentro da área do parque foi ficando inviável. Daí a incidência do parque na divisão das pessoas e famílias que foram embora e aquelas que permaneceram, umas resistindo bravamente, outras abrindo mão do trabalho na roça e da caçaria. O tempo do parque contempla concomitantemente a paulatina mudança para um estilo de vida mais urbano no caso dos que saíram e o cerceamento de uso dos recursos para aqueles que optaram por permanecer na área.

Porém, as restrições sobre o espaço não mantiveram um nível de tensão permanente, elas dependeram dos programas e objetivos dos diferentes períodos que têm marcado a história do PEPB e da capacidade real de controle por parte dos administradores do parque que, por exemplo, nem sempre têm tido um time contínuo e numeroso de guardas florestais para patrulhar a área. Deste modo, as restrições se flexibilizavam ou se agudizavam, deixando brechas para as práticas espaciais de uma população que nunca foi totalmente passiva às imposições de uso do espaço ditadas pelo parque.

As interdições sobre os usos do espaço na área do parque também se dirigiram contra a construção de novas moradias e a utilização de materiais que oferecem maior durabilidade como tijolo e cimento, inibindo as famílias expandidas à extensão do teto da casa paterna. Ao se casarem, o filho ou a filha, mais frequentemente o primeiro, passam a 
morar numa casa colada ou apregada, que consiste inicialmente no acréscimo, "parede com parede", de um novo cômodo que tem entrada independente. As restrições impostas pelo parque atentaram contra quaisquer ampliação ou remodelação nas vivendas. Construção de laje e segundo andar, instalação de varandas e colocação de pisos cerâmicos, dentre outras melhorias, são impedidas e continuam sendo motivo de onerosas multas aplicadas sobre os moradores por parte do INEA.

A contragosto dos seus moradores, casas de pau a pique com teto de sapê e chão de terra batida ainda subsistem no interior do maciço; querendo modernizá-las, seus habitantes temem remodelá-las pelos ônus extras que podem vir a acarrear. Essas construções, sobrevivências do tempo de antigamente, são enxergadas de diferentes formas. Prova da centenária presença de moradores dentro do parque, elas são celebradas pelos visitantes de fora que se admiram pela possibilidade de ver uma amostra do passado no presente e pedem pela sua conservação, enquanto seus habitantes sonham em ter acesso à modernidade material contemporânea representada por paredes lisinhas, chão sem poeira, telhados sem goteiras, fios de eletricidade e água encanada.

Para Fernandez (2009), a criação do PEPB carrega o paradoxal efeito de prorrogar usos rurais tradicionais que de outra forma estariam extintos, ao limitar a extensão das áreas de cultivo e os avanços tecnológicos para a agricultura. Nesse sentido, ao tentar proteger ambientalmente a área, ainda que nem sempre com sucesso, diante do processo crescente de especulação imobiliária tão presente na zona oeste carioca, o PEPB criou as condições para a perpetuação de alguns traços pertencentes a um modo de vida caipira no meio da cidade, ou melhor, manteve aspectos caraterísticos do tempo do banco dentro do tempo do parque; uma situação que se define pela sua incapacidade de subordinação completa às racionalidades dominantes.

A delimitação de uma unidade de conservação a partir da cota de 100 metros esteve longe de fundar um tempo totalmente novo e criar uma paisagem homogênea. Pelo contrário, Vargem Grande é um espaço híbrido e a área correspondente ao parque é uma mistura de tempos e retalhos que reúne feições urbanas e rurais, caipiras e modernas que moldam de maneira contrastante riquezas e pobrezas. 
Agricultores que moram em casas de pau a pique e transportam sua produção agrícola no lombo de burro não seriam o único retrato fiel da atual Vargem Grande. Tal representação deixaria por fora as resistências que têm conseguido, à revelia das multas do INEA, melhorar pelas próprias mãos os caminhos para permitir o acesso de veículos motorizados, assim como também esconderia as vitórias que alguns moradores têm conquistado ao conseguir modificar e ampliar suas casas usando materiais modernos, como janelas de vidro, portões metálicos e telhas de amianto.

Por outra parte, do lado de moradores tradicionais que trabalham na cidade e habitam casebres de uma única planta com aspecto de obra inconclusa, e que pela impossibilidade de oficializar acesso a serviços públicos recorrem ao uso de energia elétrica ilegal, também estão as luxuosas mansões residenciais e os casarões de recreio com piscinas pertencentes às classes mais abastadas. $O$ contraste entre esses diferentes modos de habitar fala, pela sua vez, da iniquidade da aplicação das leis de conservação ambiental que regem para os habitantes mais pobres, ao mesmo tempo que faz vista grossa para moradores com maior poder aquisitivo ou com poder de corrupção das autoridades ambientais. A perversão desses dois modos de habitar expõe, pela sua vez, a mistura dos tempos no local. Pois aqui convivem altas modernidades com pessoas que parecem saídas do século XIX, apontou Pingo numa das entrevistas.

Não se pode pensar Vargem Grande como um bairro isolado do fluxo da metrópole, nem olhar os lavradores da área do parque como uma comunidade encerrada numa ruralidade autônoma, pois os contatos com a cidade têm sido permanentes, sendo a participação dos lavradores no circuito de feiras livres e ambulantes na zona oeste uma das manifestações mais intensas dessa conexão.

Em outro sentido, o movimento contrário, do urbano para o rural também aconteceu mediante duas formas. Em primeiro lugar, a procura de casas de campo para o lazer no meio da floresta, por parte das camadas da classe média alta carioca. Em segundo lugar, essa volta ao campo também se deu pelos movimentos de artistas plásticos e do mundo da música que foram à Vargem Grande e outras localidades em busca de inspiração para suas criações. Novos baianos e artistas plásticos como Rosa Corrêa e Hélio Oiticica, por exemplo, promoveram durante a década dos anos de 1970 o 
convívio entre o tradicional e o moderno a partir das intensas relações de amizade e de alianças de parentesco que estabeleceram com os moradores locais da época.

O tempo do parque não é monolítico, tem se transformado, revelando entre outras feições as mudanças que vem sofrendo o ambientalismo conservador. Não sendo o objetivo analisar neste espaço essas transformações, vale a pena ressaltar a forma como as pessoas as percebem. Os habitantes destacam levas de pesquisadores e representantes de ONGs que sondam projetos e efetuam intervenções pontuais. Visitas de grupos de alunos de escolas e de universidades também caracterizam esse tempo em que as lutas sociais têm desafiado o ambientalismo conservador a partir do trabalho em redes dos mais variados atores, articulados para intervir na política ambiental e urbana. Deste período, interessa ressaltar que ele é visto por alguns moradores como o tempo da gente, em que a participação dos agricultores, organizados primeiramente em uma cooperativa agrícola, e, depois, no próprio movimento quilombola, Ihes permitiu estar em contato com informações e atores como ONGs com as quais iniciaram parcerias e assessorias para experimentar novas alternativas de produção e gestão do ambiente.

Uma ação que pode ser descrita neste sentido foi a data, qualificada por Sandro como histórica, em que o Secretário Estadual do Meio Ambiente, André Corrêa, visitou o quilombo e conheceu os moradores. Nesse dia, 8 de julho de 2016, uma placa era instalada, reconhecendo o quilombo como comunidade tradicional, assim como sua presença centenária. A colocação da placa acompanhava a reinauguração de uma antiga guarita do parque, há muitos anos abandonada, e a montagem de uma cancela que espera ajudar no regulamento do fluxo de visitantes, bloqueando o acesso de carros às cachoeiras, que em dias lotados impediam a circulação dos próprios moradores. Trata-se de um pedido antigo da comunidade e que ao se concretizar, junto a uma placa oficial do parque, constitui-se em um marco da mudança de posicionamento do Estado com os habitantes do maciço.

O advento da organização quilombola criou um clima mais ameno e participativo, menos hostil e, aos poucos, mais sensível às demandas da população nativa. Algumas pessoas explicaram que as tensões têm diminuído e que, em parte, sentem-se respaldadas por uma instância de peso maior em nível federal. O processo identitário, 
admitem as lideranças, tem rendido seus frutos e trazido benefícios inesperados, é como se tivéssemos começado a existir, pois em frente a várias instituições a palavra quilombo atua como passe de mágica abrindo portas, atraindo parcerias, pesquisadores e serviços que nem imaginávamos, afirma Pingo.

Nem todo mundo enxerga este novo tempo de forma positiva; para alguns moradores menos entusiastas, o atual é um momento de muita circulação, muita informação, muita gente de fora e muita reunião, referindo-se ao contexto de intervenções vindas de fora e seus peculiares formatos para instigar a participação dos moradores na tomada de decisões e na sua organização política. Também é um tempo de introdução de novas linguagens em que a agricultura orgânica, a agricultura urbana e a agrossilvicultura são apresentadas como estratégias para enfrentar, entre outras questões, as arbitrariedades cometidas pelos administradores do parque e os gestores das políticas urbanas cariocas.

Contudo, a participação dos lavradores nestas redes de mobilização gerou, entre outras coisas, uma mudança no que diz respeito ao olhar sobre si mesmos, assim como o despertar de uma autoconsciência coletiva, identitária e patrimonial. Nesse sentido, Joel Candau (1998) argumenta que não pode haver identidade sem memória porque somente esta permite a autoconsciência da duração. Para o autor, o estabelecimento de relações entre estados sucessivos do sujeito individual ou coletivo é impossível se este não tem, $a$ priori, um conhecimento da cadeia de sequências temporais com significado para ele.

O tempo dos escravos emerge nesse contexto como uma categoria que designa um tempo originário ou lendário, que pela sua profundidade temporal se apresenta distante e cheio de lacunas. Foram comuns os depoimentos que faziam referência ao fato de que os antigos omitiram qualquer referência do tempo dos escravos. Não era algo comentado pelos mais antigos, só agora que venho a saber disso, explica Neuzinho. Isso eu não alcancei, respondiam os mais velhos quando perguntados. Para alguns, a escravidão soava incrível, é o caso de Maria Cristina de Morro Redondo. Para ela, a escravidão tratava-se de uma ficção, isso só na televisão, não pode ser verdade um humano ser escravo de outro, me explicava em uma conversa. Maria não era a única; para muitos, a escravidão trata-se de um capítulo que de tão perverso não poderia ser real, só uma ficção ou algo 
para esquecer. Nesse sentido, Mattos (2005-2006) tem advertido que silenciar o passado escravo foi uma forma de evitar o estigma; ele traduz a dificuldade de elaborar a memória de uma vivência traumática e estigmatizadora.

Para os mais novos a experiência pessoal e a tradição familiar vem sendo ressignificada frente à memória do cativeiro, provocando neles perguntas sobre a relação de seus antepassados com as fazendas dos beneditinos. Um tempo de poucas memórias vividas, mas que ancora o grupo a uma corrente de reflexão mais profunda que é a experiência coletiva da escravidão. O atual seria, então, um momento de reelaboração consciente de memórias a respeito de si, um processo pouco fácil. Hebe Mattos assume que essa identificação coletiva é processo de elaboração e só pode ser compreendida considerando contextos históricos e políticos. "Tanto o silêncio sobre a cor como ética social, quanto sua reivindicação, hoje, como bandeira de luta, são frutos diferentes da presença difusa do racismo na sociedade brasileira em suas complexas relações com a memória do cativeiro" (MATTOS, 2005-2006, p. 111).

No caso que analisamos, o tempo dos escravos também possui uma materialidade, trata-se das ruínas da fazenda de Vargem Grande, que se escondem na floresta. Desse tempo também sobreviveram os vestígios de um antigo porão onde, segundo se conta, os escravizados eram punidos, segundo se ouvia dizer essas ruínas eram desestimadas pelos mais velhos, as pessoas de antes não ligavam para elas, explica Sandro. Ambos os locais, destruídos pelo tempo, são convocados para completar as memórias e explicar a permanência e a continuidade do grupo no tempo. Referindo-se às ruínas, Halbwachs (1989) explica que elas funcionam como rastros e vestígios da sociedade na sua forma anterior e têm o poder de evocar ao grupo presente outros tempos.

Uma outra conexão com o tempo dos escravos é estabelecida, como enunciado acima pela via do sagrado. Esse universo já foi acessado de forma mais ritualística e transcendental mediante as relações afetivas e espirituais que os antigos mantiveram com Pai Tertuliano, especialmente durante o período de auge do terreiro. O período de funcionamento desse terreiro chefiado por Celso e Astrogilda correspondeu ao tempo do banco. Desativado o terreiro na atualidade, Pai Tertuliano vem exercendo um papel 
político simbolizando um elo entre o presente quilombola e o passado escravista (Rodríguez, 2017).

Daquele terreiro restam mais do que memórias: objetos como o oratório em madeira com as imagens e figuras de santos e orixás, a escultura de Pai Tertuliano, principal guia da casa, entre outros, formam em conjunto um valioso patrimônio familiar que, como analisado em outro momento (Rodríguez, 2017) se tornou acervo do museu comunitário, uma possibilidade de aceder hoje aquela temporalidade mais distante e narrar num espaço museográfico a sua trajetória como grupo.

Ao longo desta reflexão, procurei expor a representação coletiva do tempo e os marcos da memória coletiva mediante os quais os atuais moradores da Serra de Vargem Grande constroem e evocam suas lembranças e mudanças históricas. O olhar lançado pelos quilombolas sobre o passado é tributário de esquemas compartilhados de percepção sobre o tempo, as durações e as convenções de que eles são objetos, produzidas sobre condições sociais definidas, tais como a criação do parque e a mobilização social para o reconhecimento como comunidade remanescente de quilombo. A periodização das memórias dessas famílias entrecruza os tempos privados e geracionais privados com o tempo público, nos permitindo compreender como ele é interpretado e representado socialmente, informando não só as temporalizações que operam a partir do ritmo da vida coletiva, mas outras formas de conhecimento e de classificação do tempo. 


\section{Referências}

ANDRADE FRANCO, José Luís de; DRUMMOND, José Augusto; CORRÊA, Armando Magalhães. Gente e natureza de um sertão quase metropolitano. História, Ciências, Saúde. Rio de Janeiro, v. 12, n. 3, p. 1033-1059, set./dez., 2005.

ARRUTI, José Maurício. Quilombos. In: PINHO, Osmundo (Org.). Raça: perspectivas antropológicas. Campinas: ABA: Ed. Unicamp: EDUFBA, 2008.

BENJAMIN, Walter. Sobre alguns Temas em Baudelaire, In: Charles Baudelaire: um lírico no auge do capitalismo. Obras Escolhidas. São Paulo: Brasiliense, v.3, 1989, p.103-149.

CANDAU, Joel. Mémoire et Identité. Paris: PUF, 1998.

CONSELHO CONSULTIVO DO PARQUE. Posicionamento do Conselho Consultivo do Parque Estadual da Pedra Branca sobre a elaboração do Plano de Manejo, 2012. Disponível em: <http://sertaocarioca.org.br/2012/06/posicionamento-do-conselhoconsultivo-do-parque-estadual-da-pedra-branca-sobre-a-elaboracao-do-plano-de-manejo >. Acesso em: 15 mar. 2016.

CORRÊA, Magalhães Armando. O Sertão Carioca. Rio de Janeiro: Edição do Instituto Histórico e Geográfico Brasileiro, 1936.

DORIA, Júlio Cesar de Souza. Associativismo negro no Rio de Janeiro (1883-1920): cidade e campo. Rio de Janeiro: 2017. No prelo.

FERNANDEZ, Annelise. Do Sertão Carioca ao Parque Estadual da Pedra Branca: a construção social de uma unidade de conservação à luz das políticas ambientais fluminenses e da evolução urbana do Rio de Janeiro. 2009. Tese (Doutorado em Sociologia) - Universidade Federal do Rio de Janeiro, PPGAS/IFCS, Rio de Janeiro, 2009.

FERNANDEZ, Annelise. O sertão virou parque: natureza, cultura e processos de patrimonialização. Estudos Históricos. Rio de Janeiro, v. 29, n. 57, p. 127-146, jan./abr., 2016.

FONSECA, Maria Cecilia. Da modernização à participação. A política federal de preservação nos anos 70 e 80 . Revista do Patrimônio Histórico, Artístico e Nacional, n. 24, p. 159, 1996.

FRIDMAN, Fania. Donos do Rio em nome do Rei: uma história fundiária da cidade do Rio de Janeiro. Rio de Janeiro: Jorge Zahar Editor, Garamond, 1999. 
GOMES, Flávio; DOMINGUES, Petrônio. Histórias dos quilombos e memórias dos quilombolas no Brasil: revisitando um diálogo ausente na Lei 10.639/031. Revista da ABPN, v. 5, n. 11, p. 5-28, jul./out., 2013.

GOW, Peter. Of mixed blood: kinship and history in Peruvian Amazônia. Oxford: Claredon Press, 1991.

HALBWACH, Maurice. A memória coletiva. São Paulo: Centauro, 1989.

HARTOG, François. Regimes de historicidade: presentismo e experiências do tempo. Belo Horizonte: Editorial Autêntica, 2013.

HONNETH, Axel. Luta por reconhecimento: a gramática moral dos conflitos sociais. São Paulo: Editora 34, 2003.

HUYSSEN, Andreas. Resistência à memória: os usos e abusos do esquecimento público. In: INTERCOM - CONGRESSO BRASILEIRO DE CIÊNCIAS DA COMUNICAÇÃO, XXVII, Porto Alegre, 30 agosto a 03 de setembro de 2004. Anais... Porto Alegre: Intercon, 2004.

LEVI-STRAUSS, Claude. O pensamento Selvagem. São Paulo: Campinas, 1989.

MATTOS, Hebe. Remanescentes das comunidades dos quilombos: memória do cativeiro e políticas de reparação no Brasil. Revista USP. São Paulo, n. 68, p. 104-111, dez./fev., 20052006.

PIETRAFESA DE GODOI, Emília. O trabalho da memória: cotidiano e história no sertão do Piauí. Campinas: Editora da Unicamp, 1999.

POLLAK, Michael. Memória, esquecimento, silêncio. Estudos Históricos. Rio de Janeiro, v. 2, n. 3, p. 3-15, 1989.

SOARES, Luiz Eduardo. Campesinato: ideologia e política. Rio de Janeiro: Zahar Editores, 1981.

VIEGAS, Nonato. O fim do sossego. Quilombola é atropelado por plano parque estadual. Revista Piauí, out., 2013. Disponível em http://piaui.folha.uol.com.br/materia/o-fim-dosossego/

RODRíGUEZ, Luz Stella. Do Caminho à Trilha. As perspectivas do lazer e do habitar na Transcarioca. Interseções. Rio de Janeiro: UERJ, v. 18, n. 1, p. 64-96, 2016. 
RODRÍGUEZ, Luz Stella. Paisagem, memória e parentesco no Quilombo de Vargem Grande. Revista Etnográfica, Lisboa, v. 21, p. 269-292, 2017 b. 